\title{
Study and Design of an Electro Technical Device for Safety on Railway Network
}

\author{
Clavel Edith, Meunier Gérard, Bellon Marc and Frugier Didier \\ G2Elab Grenoble Electrical Engineering Laboratory, \\ Saint Martin d'Hères, BP46, Saint Martin d'Hères, Cedex,
}

France

\section{Introduction}

The security on the railway network is a real important challenge since today, the number of trains is growing and the saturation of the network is close to be reached.

In this chapter, an electrical system is presented in order to improve the electrical detection of trains on the network and correctly manage the lights. That is how security is ensured.

In the next section, the context of the study is presented. The management of lights on network is explained to emphasize the possible trouble which may occur.

The third part deals with the electrical system which is experimented by the French National Railway Company to overcome this problem. The way it works and its main characteristics will be detailed.

In order to base the further developments of this solution not only on experiments, a modeling process is presented in the following part. For other industrial fields, it has proved to be efficient and its use in the case of a railway system seems possible.

In order to validate the modeling approach, an experimental set is developed since it is very difficult to make measurements in situ. It will be presented in the fifth part of this chapter.

Finally in a last section, the results of the modeling process are successfully compared to the measures.

The outlook of improving the studied system is important since the impact of some dimensional parameters on its performances is analyzed whether being geometrical or physical parameters.

\section{Context of the study}

The distance between trains on a railway is controlled by signals similar to road lights. The railroad line is divided into several sections from $1500 \mathrm{~m}$ to $20 \mathrm{~km}$. Every section is protected by a signal. When a train enters a section (1), an electrical device detects it and makes the 
light becomes red (2). When the train penetrates into the following section, its signal turns to a red light, while the signal of the first section becomes yellow (3). When the train penetrates into the third section, its signal indicates a red light. The signal of the second section gives the indication yellow, and the signal of the first section gives the indication that the way is clear by a green light 4 . So if a train is stopped in a section, the following train will meet a yellow light announcing to the driver that the following light is red. He will have to reduce the speed of the train to be able to stop if necessary. This is illustrated of Fig. 1.

As said before, an electrical system is used to guarantee this security working. It is constituted by:

- A generator connected to one of the extremities of the isolated section and which imposes a difference of potential between the two rails,

- A receptor connected to the other extremity of the isolated section which measures the difference of potential between the two rails,

- A transmission line which is electrically limited to the extremities of the considered section.

The generator sends a coded signal through the electric circuit constituted by the rails and the receptor. When the zone included between the generator and the receptor is free, the receptor is able to detect the coded signal: the way is then considered free. When a train enters this section, a great part of current is derived by wheels and axles (what we call "shuntage"); the receptor does not receive this coded signal coming from the generator anymore: the way is then considered busy. Such a device is thus able to detect the presence of trains on a section by the change of the impedance value of the circuit between the rails. When a train is on a section, the rails are short-circuited by the train and the group wheels, axles, rails 1 and 2 have lower impedance. So the measure of the voltage drop at the receptor implies a busy section. This change of electrical circuit is illustrated on Fig. 2.

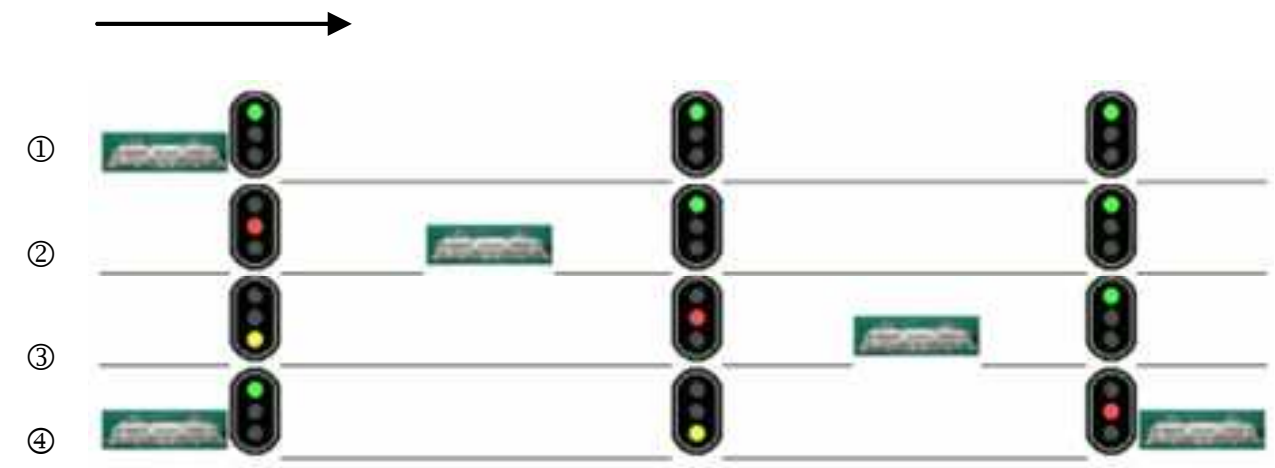

Fig. 1. The principle of railway lights 


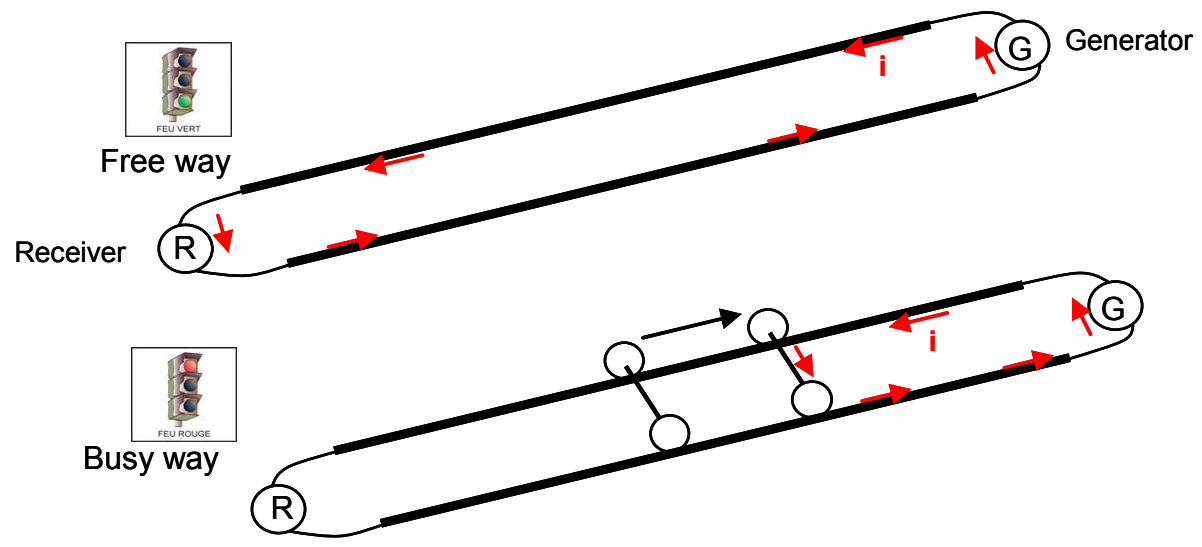

Fig. 2. The principle of the detecting electrical system

In the case of the electrified lines, which represent $90 \%$ of the French network, rails are very often used to ensure the return of drive current towards the substations. Drive currents are about 1000A. And they have to coexist with currents of $1 \mathrm{~A}$ from the detecting electrical system.

In order to be able to easily separate these two currents, the kind of current inside the detecting system depends on the electrified lines. In the case of DC lines, alternative currents are used for the detecting electrical system and in the case of alternative power supply different frequencies are used for the detecting circuit. In that case, the insulation between two detecting systems is carried out using inductive connections which allow the return of the drive current.

Current of the detecting circuits can be modulated with various frequencies, which can be detected by equipments on board the trains to give to the drivers all the indications in the cabin. This principle of the transmission between the way and the machine is used in the famous French High Speed Train (TGV).

Sometimes, the short circuit between wheels and rails is not of good quality. This is the case of weak machines, parts of the railway network rarely used, bad wheel/rail contact due to insulating body. So errors of detection by the system can lead to dangerous situations. The light is green even if there is a train in the section. If a more rapid train arrives, an accident could occur.

As a consequence, in order to be sure that the signal is well interrupted by the train on a section, the French National Railway Company (SNCF) has added an electrical device which will be described in the following part.

\section{The proposed device}

To avoid this problem of detection, several solutions have been explored:

- to replace all the detecting electrical systems,

- $\quad$ to improve the contact between the wheels and the rails. 
This last solution has been generally adopted. This can be made by cleaning the rails. A special accessory has been designed to scrape the rails.

But another way to improve the contact is to help the short circuit created by the wheels and the rails to be efficient by adding an electrical device.

This last option is the topic of this paper.

\subsection{Working principle of the inductive loop}

The principle of the proposed device is to create a voltage drop of sufficient level in order to make possible a current to flow. This is done by an inductive loop able to induce in the wheels/axles/rails circuit a current of sufficient value.

The proposed device is presented on Fig. 3. It is constituted by:

- a high frequency current controlled generator,

- a parallel LC circuit made of capacitors located on the bogies and the inductance of the inductive loop.

This loop is in fact the primary circuit of a transformer. The secondary part is constituted by the axles and the rails. The current induced by the loop flows through the axles and the rails and must be high enough to guarantee the electrical contact between the wheels and the rails. During a bad contact rail / wheel, the secondary circuit of the transformer is open and an induced voltage appears between the wheel and the rail and establishes again the electrical contact insuring the "shuntage".

The chariot near the inductive loop constitutes a third circuit of the transformer which can reduce the value of the current inside the axles - rails circuit.

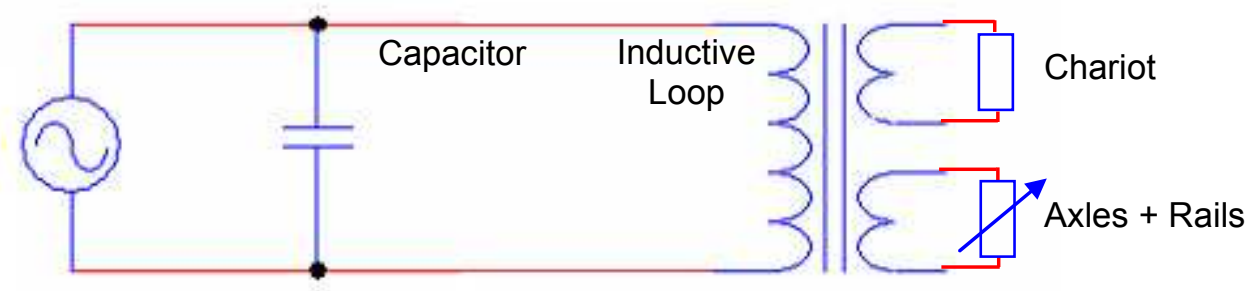

Fig. 3. The principle of the detecting electrical system 


\subsection{Electrical and mechanical requirements}

To be efficient, this system has to create a minimum voltage drop between a wheel and the rail. The working frequency of this system is imposed by the French National Railway Company. The design data for the loop are:

- minimum voltage drop : 3V,

- frequency : $147 \mathrm{kHz}$,

- $\quad$ range of frequencies : $140 \mathrm{kHz}$ to $152 \mathrm{kHz}$ (adjusted using capacitors),

- control of the current : if the current remains under a certain limit during 10s, a default signal is sent to the driver. An emergency braking is used and special rules are adopted by the driver,

- mechanical constraints (under the train, easy to access, easy to change and repair,...),

- material for the loop : copper is used and several other cables are added.

\subsection{Design of the loop}

The performances of the loop are directly linked to its geometrical size.

But the degrees of freedom are limited because a lot of mechanical constraints exist:

- the surface of the loop is limited by the space under the train,

- the height of the loop is limited by the distance between the train and the rails,

- leakage currents are flowing inside the metallic structure.

In practice, the environment of the loop changes (shunt, ballast, metallic parts ...) and the value of the inductance of the loop changes too. So the resonance frequency is modified. In order to avoid this, it is necessary to continuously adjust the frequency so that the current is sufficient inside the loop.

In order to perform this, a Phase-locked loop (PLL) is used.

Thanks to three electronic cards, every change of frequency is detected and automatically compensated:

- a ALIM card allows the galvanic insulation and adapts the voltage which supplies the system $(24 \mathrm{~V})$,

- a BIAS card controls the value of $147 \mathrm{kHz}$,

- a TFER card is a controlled amplifier for the BIAS card.

In order to reach an optimal design of the loop, experiments are not sufficient.

A modeling process has to be run in order to take into account all the requirements and desired performances.

This is the aim of the following part: to present a modeling approach.

\section{Modeling method}

As said before, the aim of the modeling process is to be able to evaluate the voltage and current in the studied structure. This implies to solve the Maxwell's equations and to establish an electrical equivalent circuit on which the circuit equations could be 
solved. In the field of electromagnetic approach, two families of modeling methods are facing:

- the finite element method (FEM),

- the integral method.

\subsection{Choice of the modeling method}

Each family of modeling method has advantages and drawbacks.

Concerning the FEM, it is well known and gives good results on the evaluation of the electromagnetic fields everywhere in the space. But it requires the meshing of all the space, i.e. the studied structure but also the air around. Moreover good results imply a good use of the formulations and assumptions at the limits of the studied domain. The results are principally the electromagnetic fields. Then to obtain the electrical equivalent circuit, postprocessing evaluations have to be done.

Concerning the integral methods, the only meshing of the conductive parts makes them very attractive. The number of unknowns is limited. Moreover, an electrical equivalent circuit can directly be deduced from the solving.

The most famous integral methods are the method of moment (MoM) and the PEEC method (Partial Element Equivalent Circuit).

Since the studied structure could be very large and the amount of air around significant, the use of FEM could lead to solve problems with too high a number of unknowns.

So an integral method is chosen to model the studied structure and more particularly the PEEC method which is detailed in the following paragraph.

\subsection{Principle of the PEEC method}

The PEEC method was firstly introduced by A. Ruehli (Ruehli, 1974). Based on low frequency exact analytical formulae, it consists in extracting the electric parameters from the geometries of conductors. This allows taking into account the electrical parasitic effects of interconnections while evaluating the electromagnetic behavior of an electronic or electrical system.

Full PEEC method takes into account resistive, inductive and capacitive parts.

\subsubsection{Assumptions}

According the frequency range of the study, the electrical equivalent model could be more or less complicated. Indeed for not so high frequencies, only resistive and inductive effects of cabling are involved in the electromagnetic behavior of the studied system. That is why it is possible to partly use the PEEC method which allows reducing the size of the equivalent model. For the present studied application, frequency is low enough (around some $\mathrm{kHz}$ ) to limit the evaluation to the resistive and inductive parts.

Nevertheless the capacitive aspect is detailed in (Ardon et al., 2009) to complete the study. 
The mains equations will be detailed in the following paragraph to obtain the equation (13) which is the base to establish the electrical equivalent circuit.

In order to easily solve the equation (13) for each considered part, the most important assumption is that current density is uniform. But according the frequency and geometry of the studied structure, skin and proximity effects have to be taken into account during the modeling. So in a first step, all the conductors of the studied structure have to be meshed so that the current density is uniform inside each mesh.

Moreover, as presented in (13), relative permeability $\mu_{\mathrm{r}}$ is assumed to be equal 1 . Otherwise further developments of PEEC method are presented and detailed in (Aimé et al., 2009b) and (Kéradec et al., 2005) in order to take into account magnetic material influence on current distribution.

Finally no propagation aspect is considered for this first presentation. Otherwise, another modeling method has to be applied such as rPEEC or transmission lines approach (Antonini et al., 2007) and (Clavel et al., 2007).

\subsubsection{Equations and associated model}

The problem can be better formalized by considering the integral form of the Maxwell's equations and by assuming:

- quasi-static conditions;

- $\quad$ only surface location for the free-charges $\rho$;

- uniform and constant currents I in each volume element of conductors;

- constant material conductivity $\sigma$,

- vacuum permeability $\mu_{0}$ surrounding the objects;

- a homogeneous medium of permittivity $\varepsilon=\varepsilon_{\mathrm{r}} \varepsilon_{0}$;

- negligible losses in dielectric materials.

In such conditions, the following equations can be written:

$$
\begin{gathered}
\operatorname{rot} \mathbf{H}=\mathbf{J} \\
\operatorname{rot} \mathbf{E}=-j \omega \mathbf{B} \\
\operatorname{div} \mathbf{B}=0 \\
\mathbf{B}=\mu_{0} \cdot \mathbf{H} \\
\mathbf{J}=\sigma \mathbf{E}
\end{gathered}
$$

From (3), it comes:

$$
\begin{gathered}
\mathbf{B}=\operatorname{rot} \mathbf{A} \\
\mathbf{E}=-j \omega \mathbf{A}-\operatorname{grad} V \\
\Delta \mathbf{A}=-\mu_{0} \mathbf{J}
\end{gathered}
$$


(7) is the Faraday's law and (8) the Poisson's equation.

Considering a conducting volume $\Omega \mathrm{c}$ in an external electrical field $\left(\mathrm{V}_{\mathrm{ext}}\right)$, the total electrical field $E_{\text {total }}$ at any point $P$ in the conductor is given by (9):

$$
\mathbf{E}_{\text {total }}(P)=-j \omega \mathbf{A}(P)-\operatorname{grad} V_{\text {charg } e}(P)-\operatorname{grad} V_{\text {ext }}(P)
$$

$\mathrm{V}_{\text {charge }}$ is the potential due to the electrical charges in the conductor.

If, in a first approximation, the capacitive effects can be neglected, this term is null.

From (8), without propagation effects and magnetic material, it comes (10):

$$
\mathbf{A}(P)=\frac{\mu_{0}}{4 \pi} \int_{\Omega c} \frac{\mathbf{J}}{r} d \Omega
$$

where $\mathbf{J}$ is current density and $\mathrm{r}$ the distance between the integration point and $\mathrm{P}$.

Taking (5) and (10) in (9) gives (11):

$$
\frac{\mathbf{J}(P)}{\sigma}+j \omega \frac{\mu_{0}}{4 \pi} \int_{\Omega c} \frac{\mathbf{J}}{r} d \Omega=-\operatorname{grad} V_{e x t}
$$

In order to reach the desired model, it is necessary to suppose a uniform current density. For that, the volume $\Omega \mathrm{c}$ is divided into $\mathrm{m}$ elementary conductors. On each elementary conductor, (12) is written:

$$
\mathbf{J}_{k}=\mathbf{J}_{0 k} \cdot I_{k}
$$

$\mathrm{J}_{0 \mathrm{k}}$ is the electrokinetic solution for a $1 \mathrm{~A}$ current.

Multiplying (11) by $\mathrm{J}_{0 \mathrm{k}}$, it comes (13):

$$
\int_{\Omega c_{k}} \mathbf{J}_{0 k} \cdot \frac{\mathbf{J}_{k}}{\sigma} d \Omega c_{k}+j \omega \frac{\mu_{0}}{4 \pi} \int_{\Omega c_{k}} \mathbf{J}_{0 k}\left(\sum_{i=1}^{m} \int_{\Omega c_{i}} \frac{\mathbf{J}_{0 i} \cdot I_{i}}{r} d \Omega c_{i}\right) d \Omega c_{k}=-\int_{\Omega c_{k}} \mathbf{J}_{0 k} \operatorname{grad} V_{e x t} \cdot d \Omega c_{k}
$$

From (13), the electrical equivalent circuit of a conductor can be deduced (Fig. 4) (Ruehli \& Cangellaris, 2001).

(12) inside the first term of (13) gives (14):

$$
\int_{\Omega c_{k}} \mathbf{J}_{0 k} \cdot \frac{\mathbf{J}_{k}}{\sigma} d \Omega c_{k}=\frac{1}{\sigma} I_{k} \int_{\Omega c_{k}} \mathbf{J}_{0 k}^{2} \cdot d \Omega c_{k}
$$

Knowing (15), (16) can be deduced.

$$
\begin{gathered}
\frac{1}{\sigma} \int_{\Omega c_{k}} \mathbf{J}_{0 k}^{2} \cdot d \Omega c_{k}=R_{k} \\
\int_{\Omega c_{k}} \mathbf{J}_{0 k} \cdot \frac{\mathbf{J}_{k}}{\sigma} d \Omega c_{k}=R_{k} \cdot I_{k}
\end{gathered}
$$




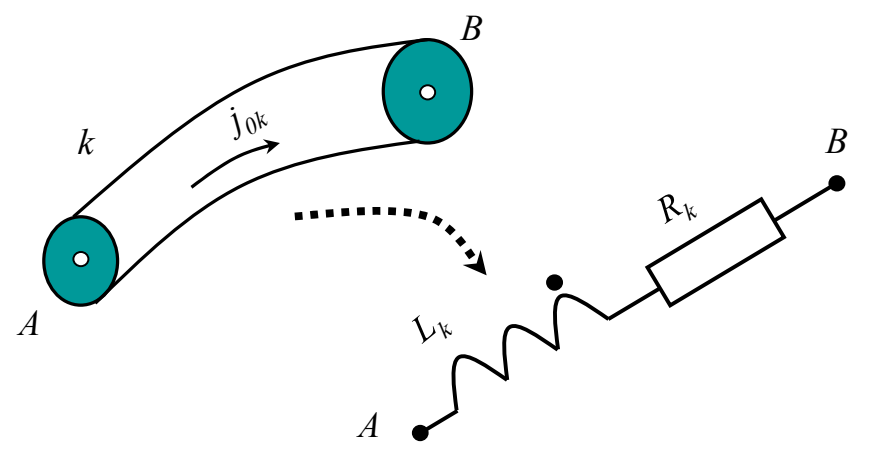

Fig. $4 \mathrm{k}^{\text {th }}$ element of the conductor

Introducing the mutual inductance between two elementary conductors $k$ and $i(17)$, the second term of (13) leads to (18).

$$
\begin{gathered}
L_{k i}=\frac{\mu_{0}}{4 \pi} \int_{\Omega c_{k}} \int_{\Omega c_{i}} \frac{\mathbf{J}_{0 k} \cdot \mathbf{J}_{0 i}}{r} d \Omega c_{i} d \Omega c_{k} \\
j \omega \frac{\mu_{0}}{4 \pi} \int_{\Omega c_{k}} \mathbf{J}_{0 k}\left(\sum_{i=1}^{m} \int_{\Omega c_{i}} \frac{\mathbf{J}_{0 l} \cdot I_{i}}{r} d \Omega c_{i}\right) d \Omega c_{k}=j \omega \sum_{l=1}^{m} L_{k l} \cdot I_{l}
\end{gathered}
$$

Concerning the term on the right of (13) the following equations can be established assuming the electrokinetic solution gives $\operatorname{div} \mathbf{J}_{0}=0$ :

$$
\begin{gathered}
\operatorname{div}\left(V \cdot \mathbf{J}_{0 k}\right)=\mathbf{J}_{0 k} \cdot \operatorname{grad} V+V \cdot d i v \mathbf{J}_{0} \\
\int_{\Omega c_{k}} \mathbf{J}_{0 k} \mathbf{g r a d} V_{e x t} \cdot d \Omega_{k}=\int_{\Omega c_{k}} \operatorname{div}\left(V_{e x t} \cdot \mathbf{J}_{0 k}\right) d \Omega_{k}=\oint_{\Gamma_{k}} V_{e x t} \cdot \mathbf{J}_{0 k} \cdot \mathbf{n}_{k} \cdot d \Gamma_{k} \\
\mathbf{J}_{0 k} \cdot \mathbf{n}_{k}=0 \\
\oint_{\Gamma_{k}} V_{e x t} \cdot \mathbf{J}_{0 k} \cdot \mathbf{n}_{k} \cdot d \Gamma_{k}=V_{a} \int_{\Gamma_{a}} \mathbf{J}_{0 k} \cdot \mathbf{n}_{a} \cdot d \Gamma_{k}+V_{b} \int_{\Gamma_{b}} \mathbf{J}_{0 k} \cdot \mathbf{n}_{b} \cdot d \Gamma_{k}=-V_{a}+V_{b}=-U_{k}
\end{gathered}
$$

with $\Gamma_{k}$ is the edge of volume $\Omega_{c_{k}} ; \mathbf{n}_{k}$ is the normal vector oriented towards the exterior of the surface, $\Gamma_{a}$ and $\Gamma_{b}$ are the current outputs surfaces.

Hence, the electrical equation is deduced (23) and (24):

$$
\begin{gathered}
-\int_{\Omega c_{k}} \mathbf{J}_{0 k} \operatorname{grad} V_{e x t} \cdot d \Omega c_{k}=U_{k} \\
R_{k} \cdot I_{k}+j \omega \sum_{i=1}^{m} L_{k i} \cdot I_{i}=U_{k}
\end{gathered}
$$


So each term of (13) leads to an electrical characteristic of conductor which is only function of its geometry.

To compute the parasitic resistance $R_{i}$ in each volume element $V_{i}$ of length $\ell_{i}$, section $S_{i}$, and resistivity $\rho$, the following analytical formula is used:

$$
R_{i}=\rho \frac{l_{i}}{S_{i}}
$$

Because of the parallelepiped shape of the elements the double integral in (17) can be expressed in an analytical form and easily computed. For the case of parallel elements, the mutual inductances $\mathrm{M}_{\mathrm{ij}}$ are computed thanks to an analytical expression. And for the general case presented on Fig. 5, the expressions (26) can be used either to evaluate $\mathrm{M}_{\mathrm{ij}}$ but also partial inductance $\mathrm{L}_{\mathrm{i}}$ if $\mathrm{a}=\mathrm{d}, \mathrm{b}=\mathrm{c}, 11=\mathrm{L} 2$ and $\mathrm{E}=\mathrm{p}=13=0$ (Hoer \& Love, 1965). If elements are not parallel an analytical/numerical integration technique is used (an analytical expression for the first integral is used, the second one being computed thanks to an adaptive gauss point integration ensuring a good accuracy). All values of $\mathrm{L}_{\mathrm{i}}$ and $\mathrm{M}_{\mathrm{ij}}$ can then be organized in a dense and square matrix [L-M] whose size is equal to the number of mesh elements (Aimé et al., 2007).

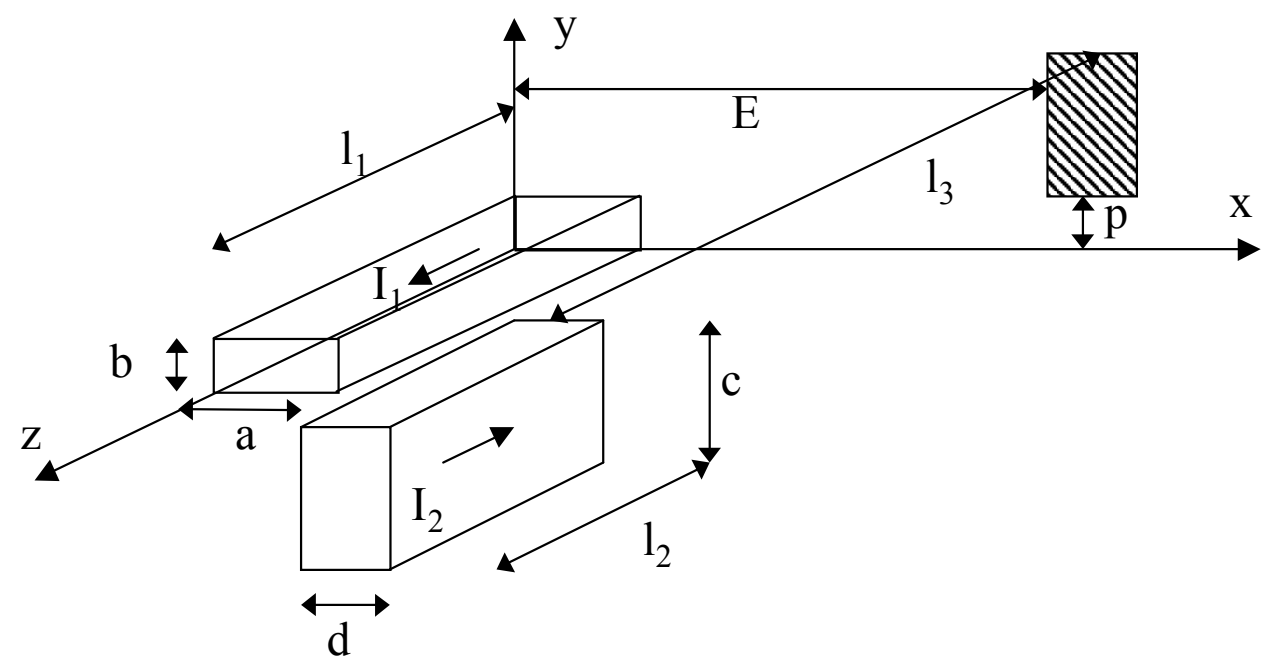

Fig. 5. General case of parallel elements for the evaluations of $\mathrm{M}_{\mathrm{ij}}$

$$
\begin{aligned}
& M_{i j}=\left[\left[[f(x, y, z)]_{E+d-a, E}^{E+d, E-a}\right]_{p+c-b, p}^{(x)} \underset{l 3+l 2-l 1, l 3}{(y)}\right.
\end{aligned}
$$

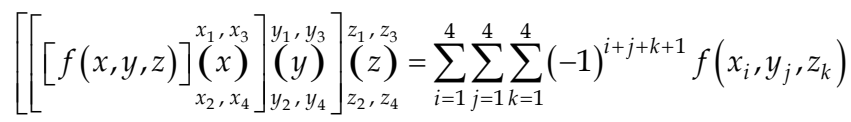




$$
f(x, y, z)=\frac{\mu_{0}}{4 . \pi} \frac{1}{a \cdot b \cdot c \cdot d}\left(\begin{array}{l}
\left(\frac{y^{2} z^{2}}{4}-\frac{y^{4}}{24}-\frac{z^{4}}{24}\right) x \ln \left(x+\sqrt{x^{2}+y^{2}+z^{2}}\right)+ \\
\left(\frac{x^{2} z^{2}}{4}-\frac{x^{4}}{24}-\frac{z^{4}}{24}\right) y \ln \left(y+\sqrt{x^{2}+y^{2}+z^{2}}\right)+ \\
\frac{\left(\frac{y^{2} x^{2}}{4}-\frac{y^{4}}{24}-\frac{x^{4}}{24}\right) z \ln \left(z+\sqrt{x^{2}+y^{2}+z^{2}}\right)+}{60}\left(x^{4}+y^{4}+z^{4}-3 y^{2} x^{2}-3 y^{2} z^{2}-3 x^{2} z^{2}\right) \sqrt{x^{2}+y^{2}+z^{2}}- \\
\frac{x y z^{3}}{6} \operatorname{Arctan} \frac{x y}{z \sqrt{x^{2}+y^{2}+z^{2}}}-\frac{x y^{3} z}{6} \operatorname{Arctan} \frac{x z}{y \sqrt{x^{2}+y^{2}+z^{2}}} \\
\frac{x^{3} y z}{6} \operatorname{Arctan} \frac{z y}{x \sqrt{x^{2}+y^{2}+z^{2}}}
\end{array}\right)
$$

The evaluation of the electrical equivalent circuit of the meshed structure has been implemented into the dedicated software InCa3D® which offers a robust and fast solver combined to a user friendly and efficient graphical interface.

For simple shapes of elements, analytical formulations (25) and (26) are used. But if the geometrical configuration is more complex, a numerical technique is used to find the values of the equivalent circuit.

\subsubsection{Meshing techniques}

In order to properly describe the current distribution inside conductors, an adapted meshing technique has to be applied. Indeed the shape of conductors often allows the assumption of $1 \mathrm{D}$ or 2D current flowing inside them.

For massive bars, or cables the 1D current leads to only mesh the cross section of conductor. Since no propagation effect is described, the length of conductors has not to be subdivided (Fig. 6). For this kind of conductor, the skin effect can be taken into account concentrating the meshes on the edges of the conductors so that the number of subdivisions is not too big.

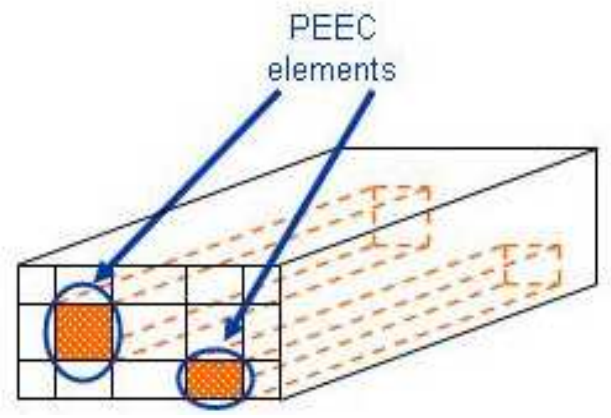

Fig. 6. The 1D meshing of conductors 
In the case of very thin and large conductors such as sheet of copper, ground plane, the 1D current assumption is no more valid. Indeed current is generally flowing in a plane so that a $2 \mathrm{D}$ approximation can be sufficient in order to properly describe the physical phenomenon. Two quadrate directions for current inside the conductor are defined. So the developed 2D meshing technique consists in dividing the plane as presented on Fig. 7.

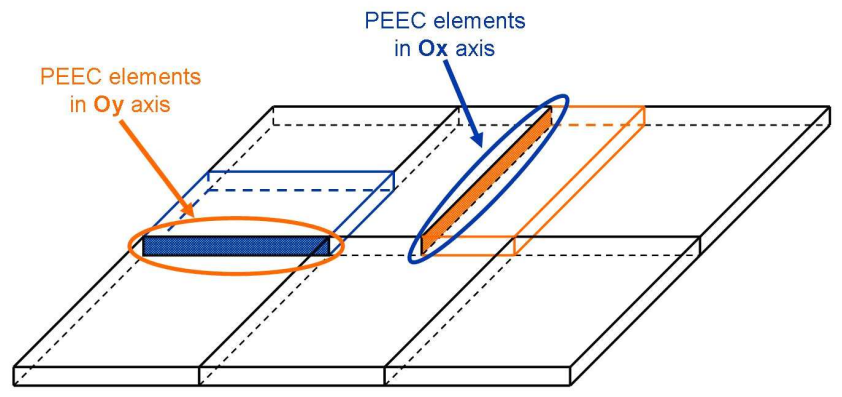

Fig. 7. The 2D meshing of conductors

For both cases, according to the shape of the cross section or conductor, a refinement meshing technique is applied so that the description is close to the real structure (Fig. 8).

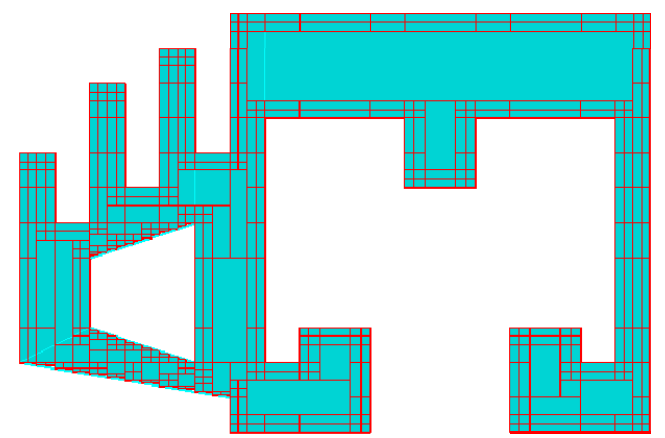

Fig. 8. Examples of meshing for complex cross section for 1D assumption

The associated electrical equivalent models for the 1D and 2D elements are summarized on Fig. 9.

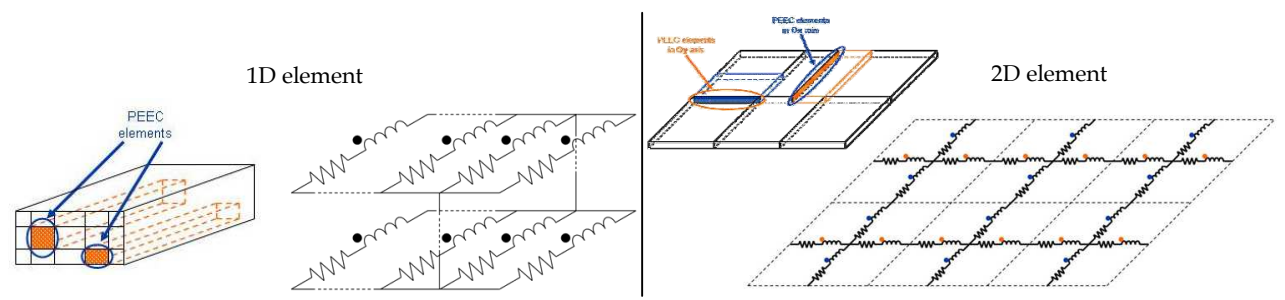

Fig. 9. R-L-M electrical equivalent circuit for 1D and 2D elements (mutual inductances are not represented on the figure) 


\subsection{Modeling process}

On Fig. 10, the modeling process of every kind of electrical structure is detailed.

It consists of four steps:

- Geometry description from designers' data or directly imported from CAD tools,

- Meshing according the appropriated assumption for the current,

- Solving the equations to obtain the electrical equivalent circuit,

- Circuit solving.

For the studied case, the unknowns are the currents inside the equivalent circuit. For that purpose it is necessary to describe the electrical environment of the problem in order to solve the right circuit equations. This last step can be achieved in a circuit solver like SPICE® or Portunus ${ }^{\circledR}$ exporting automatically the equivalent circuit inside these tools. But the size of the equivalent circuit is linked to the number of meshes and can be too big for these tools. Moreover it is not necessary to keep the information of local current inside each mesh. What is interesting is the global current inside the conductors. So a reduced equivalent circuit is better appropriated for this goal. To that aim, the user has to clearly identify the outputs of each conductor and then using parallel and series associations, the equivalent impedance between these points can be evaluated for each frequency. This reduced circuit is afterwards more practical in order to evaluate all necessary currents and voltages. Even if it is frequency dependent, a time simulation can be efficiently done. Indeed, according the frequency range, this dependence can be negligible and if not, numerical techniques to find a non dependent circuit with more components exist (Tan \& He, 2007).

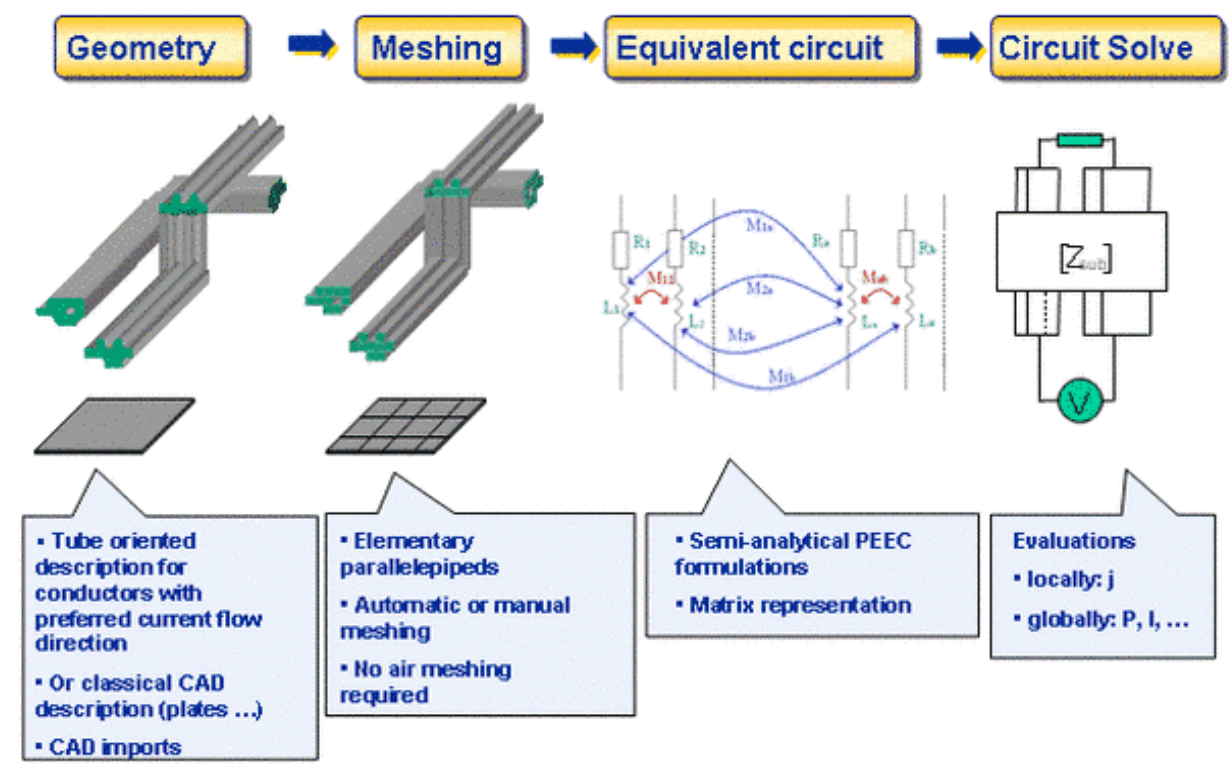

Fig. 10. Modeling process 
This proposed modeling process has proved to be very efficient not only for high current electrical systems (Gonnet et al., 2004) but also power electronics devices and structures (Aimé et al., 2009a), electronic card (Clavel et al., 2007a), PCB application (Vialardi et al., 2010) and aircraft structures (Jazzar et al., 2011).

\section{The experimental structure}

In order to validate the modeling process, experiments have been undertaken.

Unfortunately, measures on real structures are very tricky. A simplified system has thus to be defined. It is presented on Fig. 11. The chariot has been replaced by copper tubes (diameter $42 \mathrm{~mm}$ ); the rails and axles have been replaced by cables $\left(35 \mathrm{~mm}^{2}\right)$. Sizes have been chosen so that the experimental set is close to a real system (Fig. 12).

The characteristics of the voltage source are the same as described in the requirements paragraph.

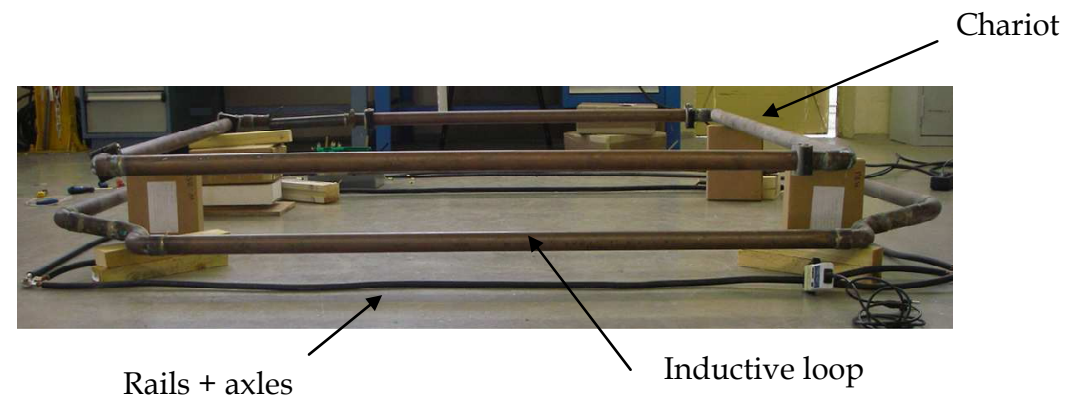

Fig. 11. The experimental system
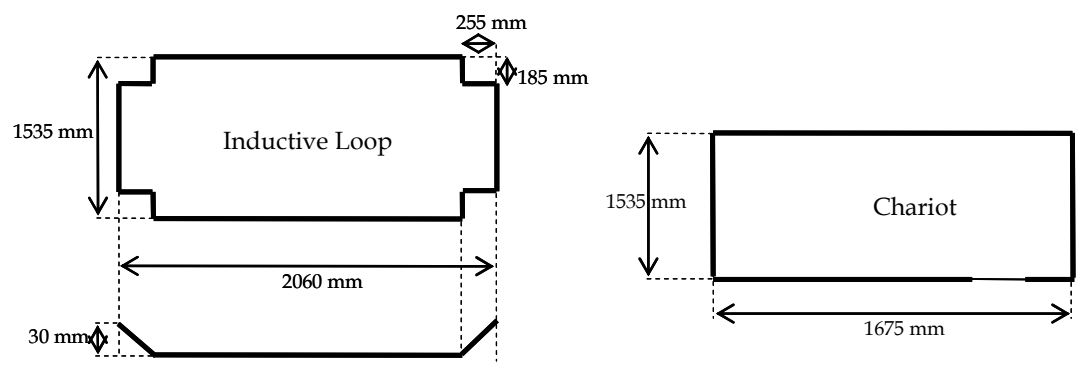

Fig. 12. Sizes of the experimental system

The measurement procedure consists in measuring (Fig. 13-14):

- current inside the chariot (so the cross section has been locally reduced in order to insert a current probe);

- current inside the inductive loop;

- $\quad$ voltage drop between the wheel and the rails (Urw). 
Different configurations have been tested and for each of them maximum data have been measured:

- $\quad$ the inductive loop alone;

- the inductive loop + rails + axles;

- $\quad$ the inductive loop + rails + axles + chariots;

- $\quad$ the inductive loop + rails + axles + chariots +4 shunts for the wheels;

- $\quad$ the inductive loop + rails + axles + chariots +4 shunts for the wheels with 4 resistors to represent the non perfect electrical contact between the wheel and the rail.

For each of them open circuit and short circuit measurements have been made.

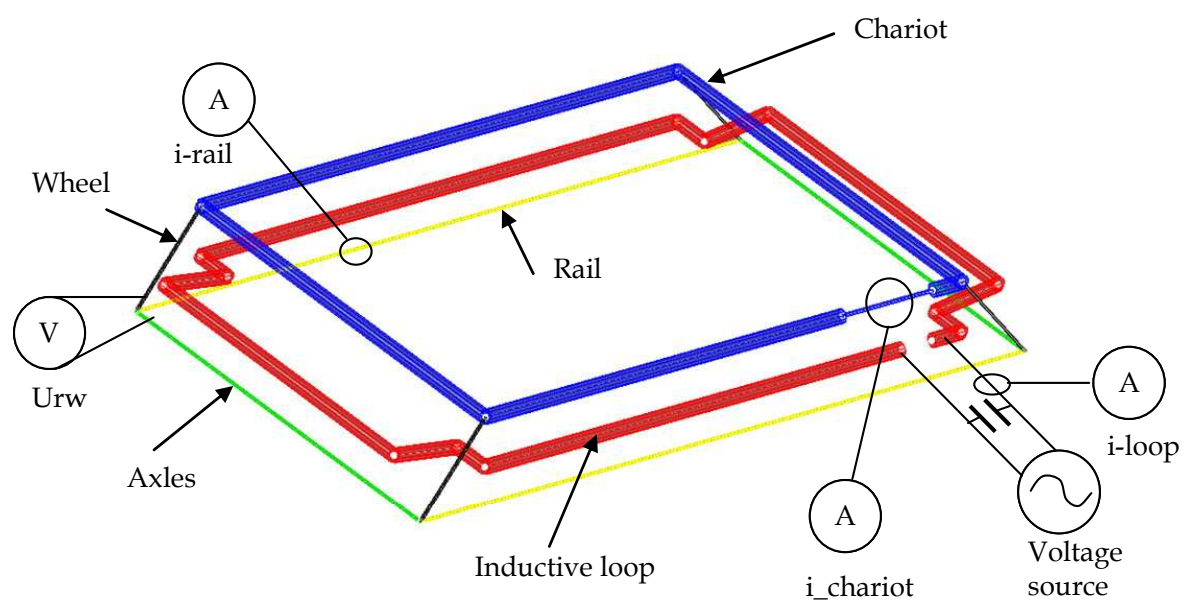

Fig. 13. Measurements procedure

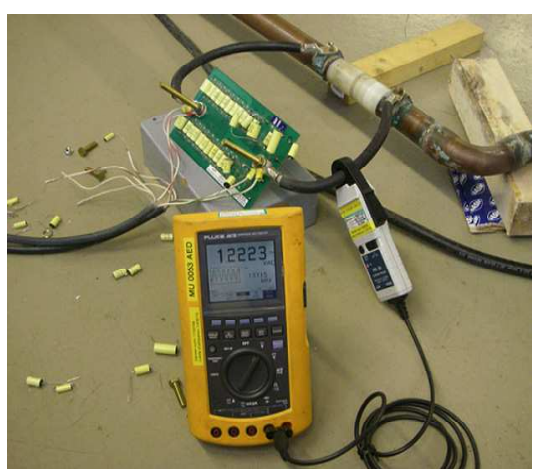

Current measure

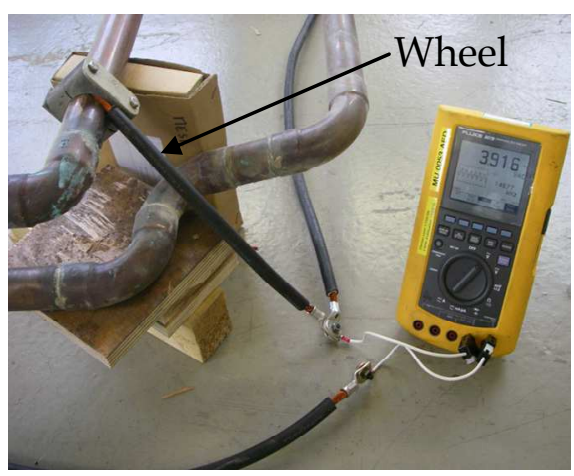

Voltage drop measure

Fig. 14. Used probes (Fluke 867B, current probe PR30)

Knowing the current I in the loop, the voltage source $V$, their phase $\varphi$ and the frequency (f, $\omega=2 \pi \mathrm{f}$ ) an equivalent circuit for the measured system can be calculated using (27) (Fig. 15). 


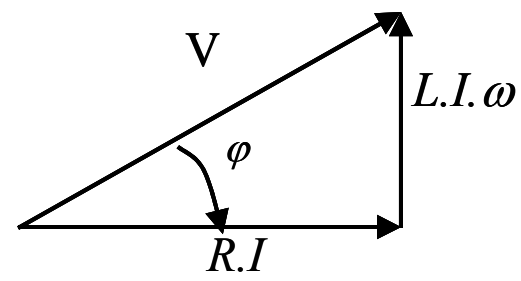

Fig. 15. Fresnel's diagram for the evaluation of equivalent circuit

$$
\left\{\begin{array}{l}
R=\frac{V \cos (\varphi)}{I} \\
L=\frac{V \cdot \sin (\varphi)}{2 \pi f . I}
\end{array}\right.
$$

The second configuration is very close to the classical case of two coupled inductances like a simple transformer. The first one is supplied with an alternative source and an induced current (short-circuit situation) or voltage (open circuit situation) is created on the second one (Fig. 16).

The theoretical study is briefly reminded in the following equations (28) with only one turn for our case $(\mathrm{n} 1=\mathrm{n} 2=1)$.

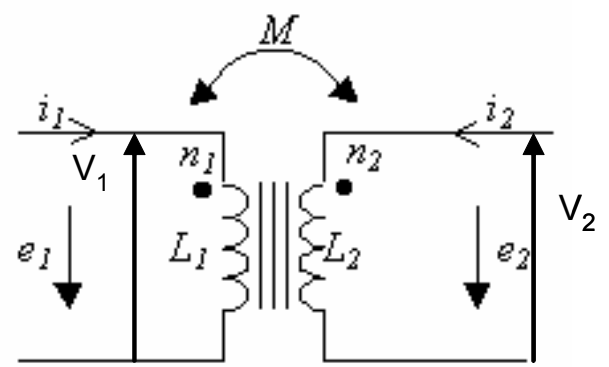

Fig. 16. The simple transformer

$$
\begin{aligned}
& V_{1}=R_{1} \cdot I_{1}+L_{1} \frac{d I_{1}}{d t}+M \frac{d I_{2}}{d t} \\
& V_{2}=R_{2} \cdot I_{2}+L_{2} \frac{d I_{2}}{d t}+M \frac{d I_{1}}{d t}
\end{aligned}
$$

The open circuit configuration gives (29). The voltage drop is directly the Urw voltage characterizing the working of the loop.

$$
\begin{aligned}
& V_{10}=R_{1} \cdot I_{10}+L_{1} \frac{d I_{10}}{d t}=R_{1} \cdot I_{10}+L_{1} \cdot I_{10} \cdot \omega \\
& V_{20}=M \frac{d I_{10}}{d t}=M \cdot I_{10} \cdot \omega
\end{aligned}
$$




\section{Results}

In this part the electrical equivalent circuit given by the modeling process is presented as well as comparisons between the circuit simulation and measurements.

\subsection{Modeling of the real system}

The CAD complete studied structure is presented on Fig. 17 on which the wheels, chariot, inductive loop clearly appear.

Indeed in order to correctly solve the problem, some geometrical simplifications have been done. The wheels, the rails and the axles have been replaced by straight massive conductors; four shunts have been added to connect the chariot to the axles in order to represent a realistic situation.

Using InCa3D, the result is presented on Fig. 18.

The geometry has been meshed in order to take into account the proximity and frequency effects.

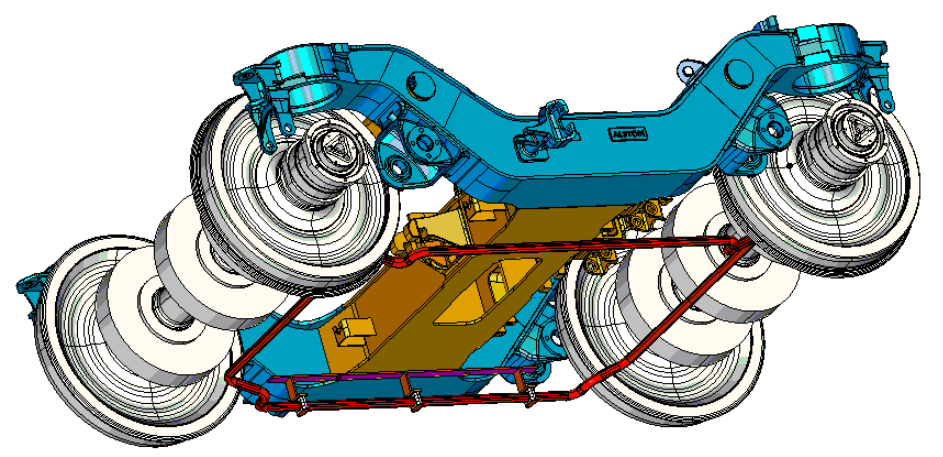

Fig. 17. The complete structure

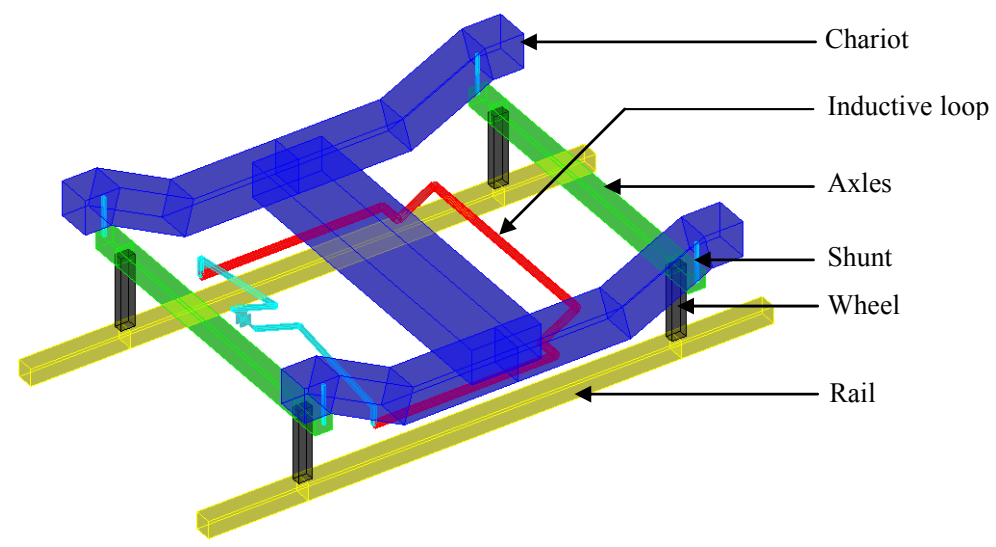

Fig. 18. InCa3D description of the studied structure 
After the PEEC solving, the equivalent circuit has been reduced in order to obtain the simple SPICE-like circuit drawn on Fig. 19 where each part of the system is well identified by an L$\mathrm{R}$ series equivalent circuit. On this circuit all the inductances are coupled with mutual coefficients but they have been cut off to make it clearer.

\subsection{Comparison between measures and simulation on the experimental set}

The experimental case has been modeled (Fig. 11) using the same process and for each configuration simulation results with the same operating conditions (value of the supply voltage source, frequency) have been compared to the measurements.

The results are presented in Table 1 for the closed circuit and Table 2 for an open one.

A good agreement between simulations and measurements can be observed.

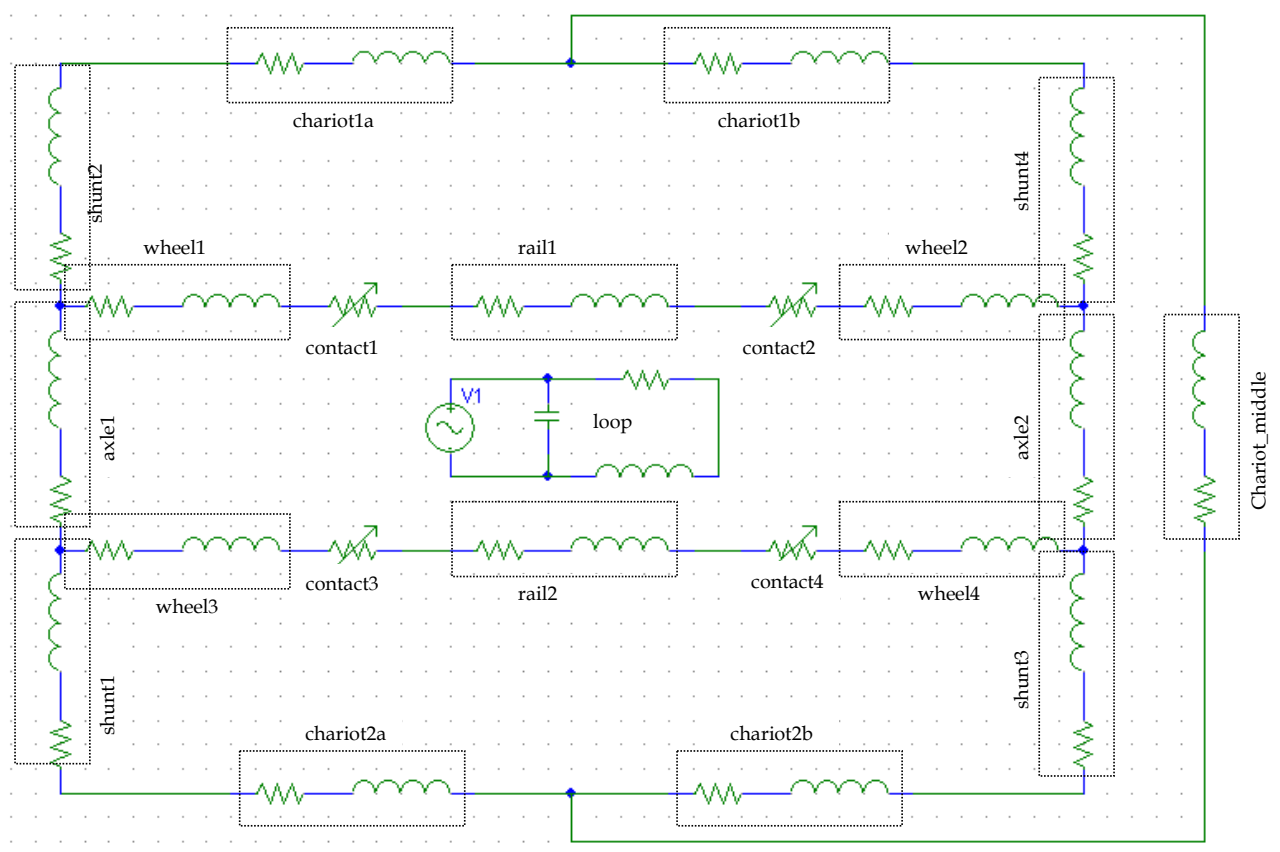

Fig. 19. Reduced electrical equivalent circuit for the studied structure (mutual inductances have been removed) 


\begin{tabular}{|l|c|c|c|c|c|}
\cline { 3 - 6 } \multicolumn{2}{c|}{} & \multicolumn{5}{c|}{ Closed circuit } \\
\hline Conditions & I_loop $(\mathrm{A})$ & $\Phi\left(^{\circ}\right)$ & $\mathrm{L}(\mu \mathrm{H})$ & $\mathrm{R}(\Omega)$ \\
\hline \multirow{2}{*}{ Only the loop } & Measure & 10.07 & -98 & 5.15 & 0.25 \\
\cline { 2 - 6 } & Simulation & 10.72 & -89.9 & 4.84 & 0.01 \\
\hline \multirow{2}{*}{ Loop + Rails + Axles } & Measure & 11.13 & -96 & 4.5 & 0.44 \\
\cline { 2 - 6 } & Simulation & 12.84 & -89.8 & 3.98 & 0.01 \\
\hline \multirow{2}{*}{$\begin{array}{l}\text { Loop + Rails + Axles + } \\
\text { Chariot }\end{array}$} & Measure & 12.6 & -95.8 & 4.05 & 0.38 \\
\cline { 2 - 6 } & Simulation & 14.65 & -89.8 & 3.5 & 0.01 \\
\hline $\begin{array}{l}\text { Loop + Rails + Axles + } \\
\text { Chariot + 4 shunts }\end{array}$ & Measure & 12.5 & -95 & 4.16 & 0.34 \\
\cline { 2 - 6 } & Simulation & 14.95 & -89.8 & 3.49 & 0.01 \\
\hline
\end{tabular}

Table 1. Current in the loop and electrical characteristics for a closed circuit - simulation and measurements

\begin{tabular}{|c|c|c|c|c|c|c|c|}
\hline & & \multicolumn{6}{|c|}{ Open circuit } \\
\hline \multicolumn{2}{|l|}{ Conditions } & $\begin{array}{c}\text { I_loop } \\
\text { (A) }\end{array}$ & $\Phi\left(^{\circ}\right)$ & $\mathrm{L}(\mu \mathrm{H})$ & $\mathrm{R}(\Omega)$ & Urw (V) & $\Delta$ urw \\
\hline \multirow{2}{*}{ Loop + Rails + Axles } & Measure & 10.8 & -95.9 & 5.21 & 0.46 & 24.1 & \multirow{2}{*}{$4.66 \%$} \\
\hline & Simulation & 11.68 & -89.8 & 4.84 & 0.01 & 25.22 & \\
\hline \multirow{2}{*}{$\begin{array}{l}\text { Loop + Rails + Axles } \\
+ \text { Chariot }\end{array}$} & Measure & 12.04 & -95.5 & 4.59 & 0.38 & 21.67 & \multirow{2}{*}{$5.45 \%$} \\
\hline & Simulation & 13.8 & -89.8 & 4.02 & 0.01 & 22.85 & \\
\hline \multirow{2}{*}{$\begin{array}{l}\text { Loop + Rails + Axles } \\
+ \text { Chariot + } 4 \text { shunts }\end{array}$} & Measure & 12.3 & -95.3 & 4.35 & 0.37 & 8.4 & \multirow{2}{*}{$1.9 \%$} \\
\hline & Simulation & 14.7 & -89.8 & 3.65 & 0.01 & 8.56 & \\
\hline
\end{tabular}

Table 2. Rail-Wheel voltage and electrical characteristics for an open circuit - simulation and measurements

\subsection{Parametric analysis}

Once the modeling process is established with satisfactory results, it is possible to make some changes to analyze the influence of some parameters on the performances of the system.

Indeed, using InCa3D, it is possible to define geometrical and physical parameters and make them varying to improve the design of the inductive loop.

For the studied structure, the following characteristics can be defined as parameters:

- height of the inductive loop;

- $\quad$ height of the chariot;

- $\quad$ size of the loop;

- $\quad$ position of the loop under the train;

- number of shunts;

- diameter of the loop;

- number of turns of the loop;

- $\quad$ resistivity of the material;

- voltage source;

- frequency;

- resistance of the wheel/rail contact.

The main performance is the rail/wheel voltage Urw. 


\subsubsection{Variation of the height}

The distance between the inductive loop and the rails is varying in this study.

On Fig. 20, results show that the lower this distance is, the higher the Urw is.

This result is quite logical since according to (30) the induced voltage is linked to the magnetic flux. And when the distance between the two loops is low this flux is maximal.

$$
e=-\frac{d \varphi}{d t}
$$

Nevertheless, the range of variation of this parameter is quite limited because mechanical constraints on the train and required standards for some sizes. There is a minimum value to respect.

By way of contrast, if the distance between the loop and the chariot decreases, the value of Urw decreases too. This is due to the fact that, as said before, the chariot creates a supplementary winding (Fig. 3) in which an induced current can be created. The inductive coupling in this case is higher than between the loop and the rails.

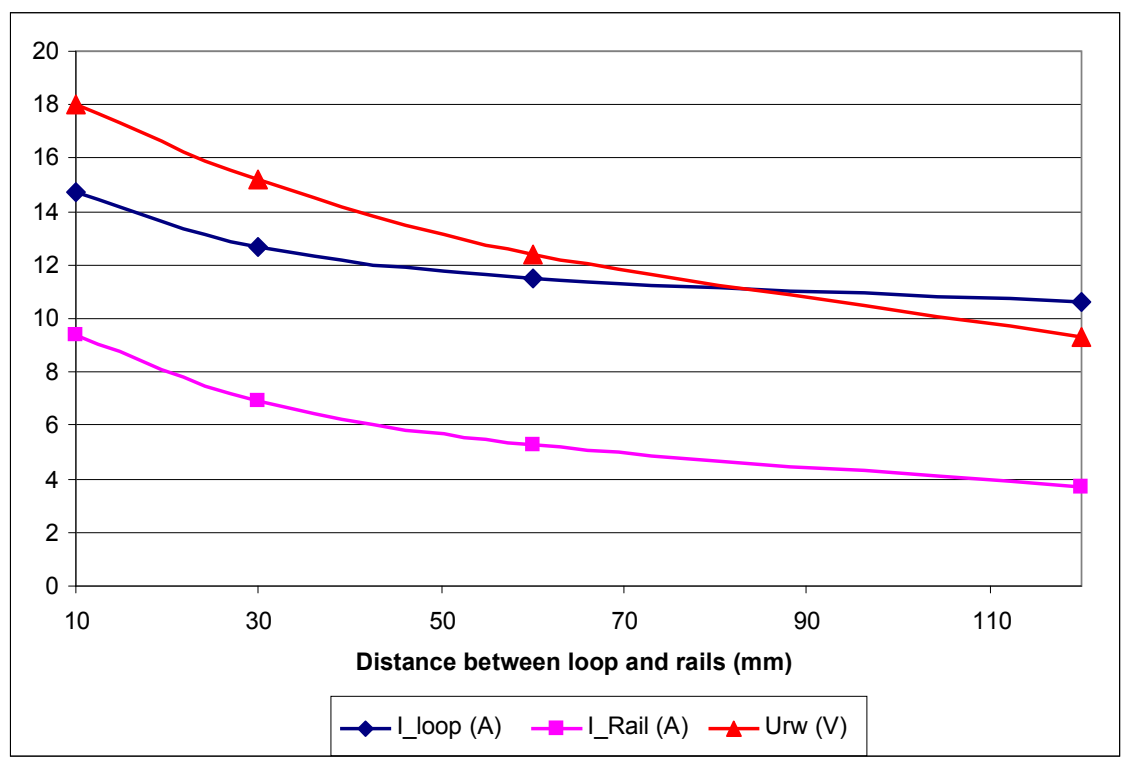

Fig. 20. Urw voltage vs. distance between the loop and the rails

\subsubsection{Variation of the sizes and the position of the loop}

On Fig. 21, three configurations have been modeled in order to evaluate the impact of the sizes and the position of the loop.

Along the simulations, it has been observed that it is essential that the loop is parallel to the rails and axles unless it performance drastically decreases. 

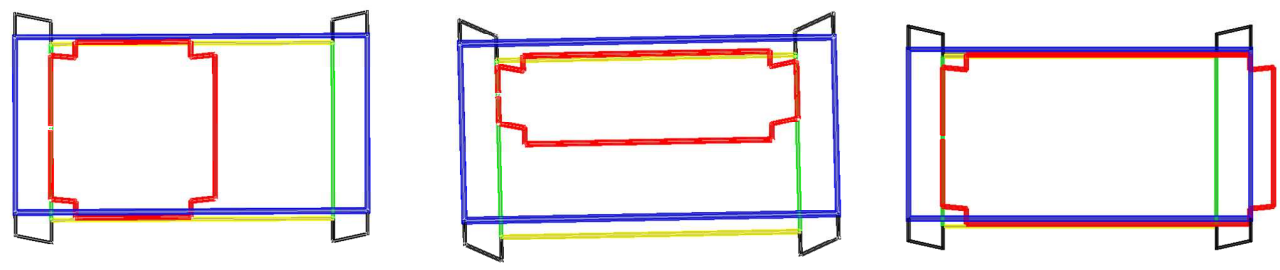

Fig. 21. Three configurations for the sizes and the position of the loop

For example, by reducing by half the length of the loop, the Urw decreases by $32.8 \%$. And by reducing by half the width of the loop, the Urw decreases between $26 \%$ and $52 \%$ (depending on the place where it is measured -close to the loop or not). If, on the contrary, the length of the loop is increased of $25 \%$, Urw decreases by $11.6 \%$.

The results obtained during these simulations confirm that the coupling between the primary constituted by the loop, and the secondary constituted by the circuit rails-axles, depends on the geometry of the loop. The purpose is obviously that the secondary circuit shares as many lines of magnetic field as possible with the primary one. Since there is no magnetic material which can guide the magnetic flux, contrary to a classic transformer, it is necessary to move as close as possible from the inductive loop of the secondary conductors to increase the coupling.

Keeping the same loop and moving it under the train so that it is no more under the chariot, the distance between the primary part and the secondary one will increase and the performances will decrease. A secondary part constituted by both rails and axles of two different chariots can also be imagined. Yet the distance between the axles of two consecutive chariots is approximately 15 meters. The length of the loop is then considerably increased, and thus its inductance (ratio 3.7). The voltage source of the loop would then be oversized to obtain an Urw voltage equivalent to that of the current loop. Moreover the cost of the loop would be drastically increased and additional mechanical constraints to fix the loop would appear.

\subsubsection{Variation of the diameter of the loop}

Keeping the same external sizes for the loop, the diameter of the copper tube has been increased in this part of the study. As presented on Fig. 22, this implies a reduction of the internal surface of the loop.
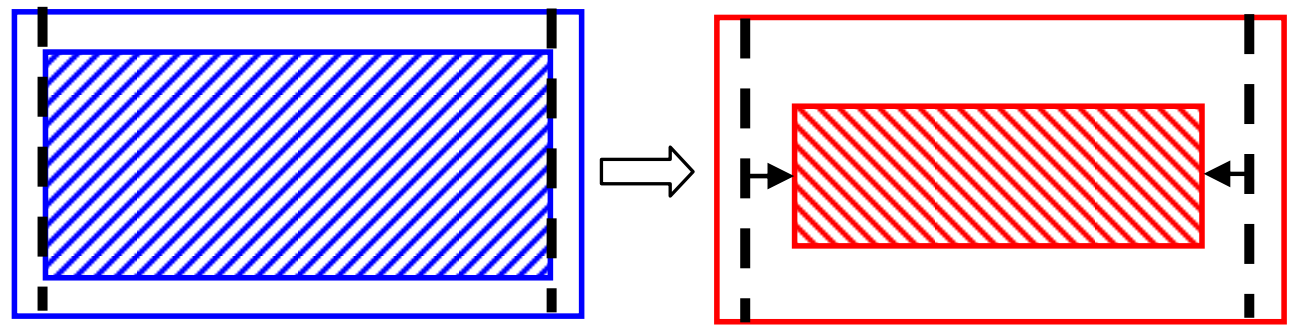

Fig. 22. Increase of the diameter $f$ the loop 
The simulations show that for a constant supply voltage the magnetic flux remains constant too. Since $\Phi=B S$, when the diameter of the tube increases the internal surface of the loop decreases. So the induction B increases. As the current is directly proportional to the induction and as $\Phi=\mathrm{LI}$, the increase of the induction leads to an increase of the current and thus a decrease of the inductance of the system.

By dividing the diameter of the tube by $2(21 \mathrm{~mm})$, the surface increases by $7.5 \%$ and the current in the loop decreases by $13.6 \%$. The inductance increases by $16.7 \%$. The result of this variation of diameter is the decrease of Urw voltage by $8 \%$.

On the contrary, if the diameter of the tube is doubled $(84 \mathrm{~mm})$, the surface decreases by $13.8 \%$, the current in the loop increases by $20 \%$. The Urw voltage increases by $8 \%$.

But it is not possible to increase this parameter too much because the increase of the current would imply more Joule losses and a higher temperature.

At this step, a question could be to determine the maximum value for the current in the loop regarding the losses but also the EMC performances of the whole system.

\subsubsection{Variation of the number of turns for the loop}

Keeping the same external shape as the current loop, a second turn has been added using a copper tube of $20 \mathrm{~mm}$ of diameter.

This additional turn considerably increases the inductance (ratio 3.7). Theoretically, the inductance is proportional to the square of the number of turn (4 in this case).

So with a constant voltage source, the current inside the loop thus decreases with the same ratio and the created magnetic field is also weaker. The Urw voltage is then decreasing by $46 \%$. So it is necessary to increase the voltage source to keep the same performances.

\subsubsection{Variation of the number of the shunts}

On Fig. 19, it is clear that the four shunts, which connect the chariot to the axles to ensure a return path for the current and protect the persons of an electric risk, introduce new loops in which current can flow.

Using simulations it is possible to connect -or not- these shunts in order to evaluate their impact on the Urw voltage.

Indeed, considering only two shunts Urw voltage increases by $110 \%$. And with only one shunt, no induced current can flow since the circuit is open and the Urw voltage increases then by $210 \%$.But since these shunts ensure the electric safety of the persons, it is not possible to eliminate them.

\subsubsection{Variation of the resistivity of the material}

Considering the results presented in Table 1, the impedance of the loop is mainly inductive , all the more because the resistive part becomes negligible since the frequency is high. 
So by changing the resistivity of material, aluminum instead of copper (ratio 1.6), no impact on the Urw voltage can be underlined.

This aspect is very interesting in an economic point of view because the loop could be made of a material cheaper than copper.

\subsubsection{Variation of the electrical contact}

To model the electrical contact between the wheel and the rail a resistor has been added because this is not a perfect short-circuit (Fig. 19).

By making the value of this resistor vary, it is possible to deteriorate the contact.

Results are presented on Table 3 for a resistance varying from $1 \Omega$ to $1 \mathrm{M} \Omega$.

For values higher than $5 \Omega$, the Urw voltage remains constant.

And for a $42 \mathrm{~V}$ voltage source, the Urw is about $3.7 \mathrm{~V}$. This characteristic has been drawn on Fig. 23 and is close to that of the voltage at the secondary winding of a transformer.

This study shows that even if the four wheels of the chariot are not in electric contact with the rails, as with a resistance of contact of $1 \mathrm{M} \Omega$, the inductive loop always allows to obtain a sufficient Urw voltage which corresponds in this case to the open circuit voltage of a transformer.

The bad quality of contacts which is one of the causes of non detection of trains inside a section is then swept away.

\begin{tabular}{|c|c|c|c|}
\hline $\mathrm{R}$ & I loop & I Rail & Urw \\
\hline $0 \Omega$ & $12.9 \mathrm{~A}$ & $2.55 \mathrm{~A}$ & $4.2 \mathrm{~V}$ \\
\hline $1 \Omega$ & $12.57 \mathrm{~V}$ & $1.50 \mathrm{~A}$ & $3.96 \mathrm{~V}$ \\
\hline $5 \Omega$ & $12.42 \mathrm{~V}$ & $0.367 \mathrm{~A}$ & $3.73 \mathrm{~V}$ \\
\hline $10 \Omega$ & $12.42 \mathrm{~A}$ & $0.185 \mathrm{~A}$ & $3.68 \mathrm{~V}$ \\
\hline $100 \Omega$ & $12.41 \mathrm{~V}$ & $1.8510^{-2} \mathrm{~A}$ & $3.68 \mathrm{~V}$ \\
\hline $1 \mathrm{k} \Omega$ & $12.41 \mathrm{~V}$ & $1.8510^{-3} \mathrm{~A}$ & $3.68 \mathrm{~V}$ \\
\hline $10 \mathrm{k} \Omega$ & $12.41 \mathrm{~V}$ & $1.8510^{-4} \mathrm{~A}$ & $3.68 \mathrm{~V}$ \\
\hline $50 \mathrm{k} \Omega$ & $12.41 \mathrm{~V}$ & $3.7110^{-5} \mathrm{~A}$ & $3.68 \mathrm{~V}$ \\
\hline $100 \mathrm{k} \Omega$ & $12.41 \mathrm{~V}$ & $1.8510^{-5} \mathrm{~A}$ & $3.68 \mathrm{~V}$ \\
\hline $500 \mathrm{k} \Omega$ & $12.41 \mathrm{~V}$ & $3.7110^{-6} \mathrm{~A}$ & $3.68 \mathrm{~V}$ \\
\hline $1 \mathrm{M} \Omega$ & $12.41 \mathrm{~V}$ & $1.8510^{-6} \mathrm{~A}$ & $3.68 \mathrm{~V}$ \\
\hline
\end{tabular}

Table 3. Comparison between simulation and measurements for an open circuit 


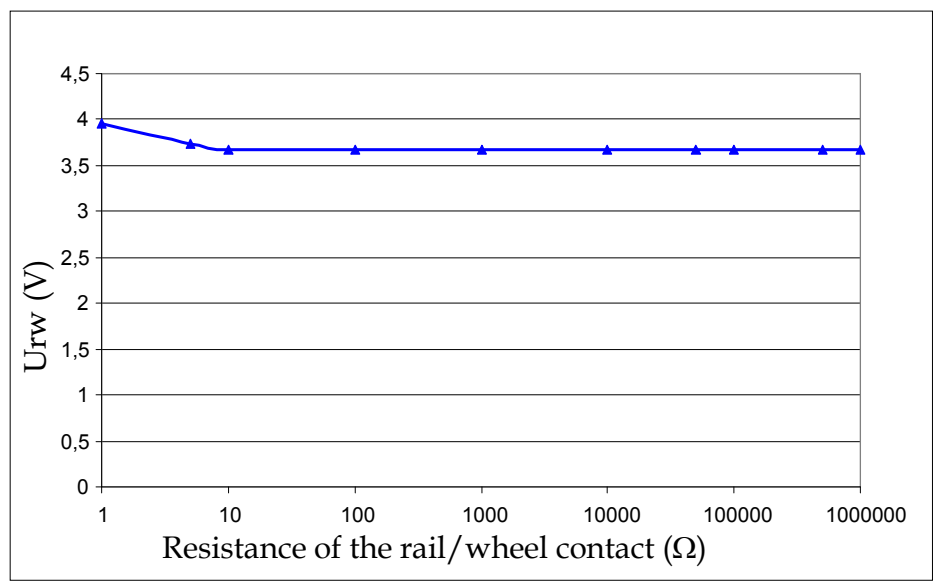

Fig. 23. Urw vs. resistance of the rail/wheel contact

\subsubsection{Variation of the frequency of the source}

The supply source of the inductive loop is a $147 \mathrm{kHz}$ sinusoidal voltage which is obtained from the $72 \mathrm{~V}$ battery embedded on the train and electronic cards. This is a specific source and no particular constraints are linked to the other electric systems embedded on the train. So it is possible to imagine a variation of the level of voltage as well as the frequency.

It is clear that, the Urw voltage is directly linked to the voltage value (proportionality). This is logical since no magnetic material has been taken into account in this study.

If there is a magnetic material, with the increase of the voltage, saturation will appear and this proportionality relation will be wrong.

Concerning the frequency, using simulations, it has been changed from $50 \mathrm{~Hz}$ to $1 \mathrm{MHz}$.

On Fig. 24 the frequency evolution of the Urw voltage is represented.

With the obtained results, since the resistive part of the loop is very low, the famous relation $\mathrm{U}=\mathrm{L} \omega \mathrm{I}$ even for low frequencies is valid. So the current into the loop could be very high for low frequency and but could decrease with increasing frequency.

And to ensure a sufficient value for the Urw voltage it must be higher than some 10A.

So compromise has to be reached to improve the inductive loop, between the values of the voltage source, its frequency, losses, possible saturation if magnetic materials are used. 


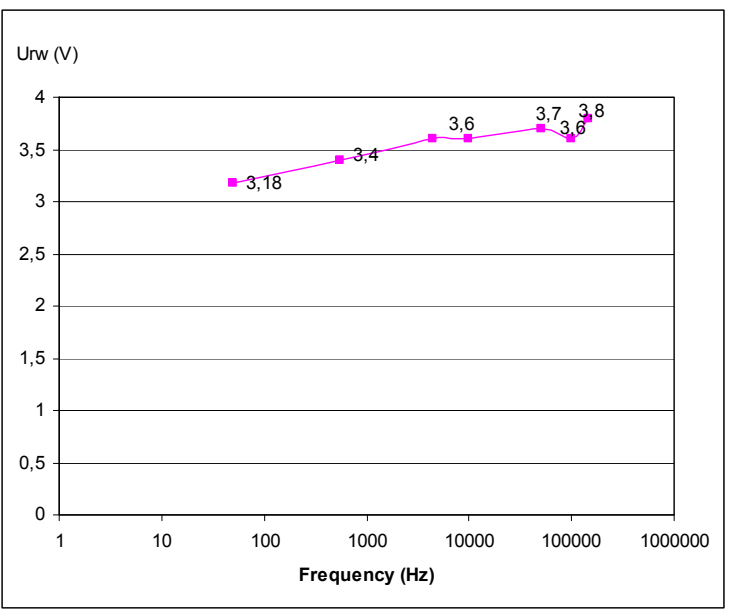

Fig. 24. Urw (V) vs. frequency $(\mathrm{Hz})$ of the voltage source

\section{Conclusions}

The number of trains on the national network is increasing. In order to ensure a maximum security, it is necessary to localize all the trains all the time.

For that purpose, the French National Railway Company (SNCF) uses an electronic detection based on the fact that the set wheel/axles/chariot short circuits the rails.

In case of a bad shuntage, an additional device is used; its working, as well as its main parameters, is studied in this article.

A modeling process is applied with the support of the PEEC method to generate a complete electrical equivalent circuit of the device. Thanks to measurements, the accuracy of the modeling approach has been validated. The influence of geometrical and physical parameters on the performances of the studied device has been analyzed in order to find the main parameters and to optimize the structure.

Future works concerning the evaluation of the supplementary losses, the modeling of magnetic material as well as the modeling of the contact wheel/rail which is not fixed but flowing have to be achieved.

\section{Acknowledgment}

Authors want to thank the French National Railway Company for its financial support for this study and its help for the experimental sets.

\section{References}

Hoer, C. \& Love, C. (1965). Exact Inductance Equations for Rectangular Conductors with Applications to More Complicated Geometries. Journal of Research C. Engineering and Instrumentation, Vol. 69C, No.2, (April-June 1965), pp. 127-137 
Gonnet, J-P.; Clavel, E.; Mazauric; V. \& Roudet, J. (2004). PEEC Method dedicated to the design of electrical systems. Proceedings of PIERS 2004 Progress In Electromagnetic Research Symposium, Pise, Italie, March 28-31 2004

Aimé, J.; Ardon, V.; Clavel; E., Roudet, J. \& Loizelet, Ph. (2009a). EMC behavior of static converters thanks to radiated field modeling using an equivalent electrical circuit. IEEE-IECON 35th International Annual Conference of the IEEE Industrial Electronics Society, Porto, Portugal, November 2-5 2009

Ruehli, A.E. (1974). Equivalent circuit models for three dimensional multiconductor systems, IEEE transaction on microwave theory and techniques, Vol. MTT 22, No.3, (March 1974), pp. 216-221

Ardon, V.; Aimé, J.; Chadebec, O.; Clavel, E. \& Vialardi, E. (2009). MoM and PEEC Method to Reach a Complete Equivalent Circuit of a Static Converter. IEEE - EMC'09, Zurich, Switzerland, January 12-16 2009

Clavel, E. \& Prémont, Ch. (2007a). Function transfer sensitivity of an electronic filter versus capacitors location on a printed circuit board. 2EMC07 Rouen, France, October 18192007

Jazzar, A.; Clavel, E.; Meunier, G.; Vincent, B.; Goleanu, A. \& Vialardi, E. (2011). Modeling and simulating the lightning phenomenon: aeronautic materials comparison in conducted and radiated modes. IEEE - ISIE11 20th International Symposium on Industrial Electronics, Gdansk, Poland, June 27-30 2011

Ruehli, A. E. \& Cangellaris, A. C. (2001). Progress in the methodologies for the electrical modeling of interconnects and electronic packages. Proc. IEEE, Vol. 89, no. 5, May 2001.

Kéradec, J-P.; Clavel, E.; Gonnet, J-P. \& Mazauric, V. (2005). Introducing Linear Magnetic Materials in PEEC Simulations. Principles, Academic and Industrial Applications. IEEE - IAS Industrial Applications Society, Hong Kong, October 2-6 2005

Aimé, J.; Tran, S-T.; Clavel, E. \& Meunier, G. (2009b). Far field extrapolation from near field interactions and shielding influence investigations based on a FE-PEEC coupling method. IEEE Energy Conversion Congress and Exposition ECCE, San José, Californie, USA, September 20-24 2009

Aimé, J.; Roudet, J.; Clavel, E.; Aouine, O.; Labarre, C.; Costa, F. \& Ecrabey, J. (2007). Prediction and measurement of the magnetic near field of a static converter. IEEEISIE 16th International Symposium on Industrial Electronics, Vigo, Spain, June 4-7 2007, pp. 2550-2555.

Antonini, G.; Deschrijver, D. \& Dhaene, T. (2007). Broadband Macromodels for Retarded Partial Element Equivalent Circuit (rPEEC) Method. IEEE Transactions on Electromagnetic Compatibility, Vol 49 , Issue: 1, 2007, pp. 35-48

Clavel, E.; Roudet, J.; Chevalier, Th. \& Postariu, D. (2007b). Modelling connections taking into account return plane: application to EMI modelling for railway. . IEEE-ISIE 16th International Symposium on Industrial Electronics, Vigo, Spain, June 4-7 2007, pp. 2526-2531.

Vialardi, E.; Clavel, E.; Chadebec, O.; Guichon, J-M. \& Lionet, M. (2010). Electromagnetic Simulation of Power Modules via Adapted Modelling Tools. EPE-PEMC 14th International Power Electronics and Motion Control Conference, Ohrid, Republic of Macedonia, September 6-8 2010.

Tan, S. X.-D.; He L. (2007) Advanced Model Order Reduction Techniques in VLSI Design, Cambridge University Press, New York, USA 


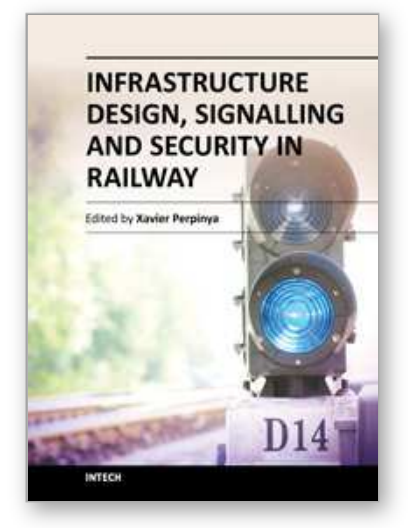

\author{
Infrastructure Design, Signalling and Security in Railway \\ Edited by Dr. Xavier Perpinya
}

ISBN 978-953-51-0448-3

Hard cover, 522 pages

Publisher InTech

Published online 04, April, 2012

Published in print edition April, 2012

Railway transportation has become one of the main technological advances of our society. Since the first railway used to carry coal from a mine in Shropshire (England, 1600), a lot of efforts have been made to improve this transportation concept. One of its milestones was the invention and development of the steam locomotive, but commercial rail travels became practical two hundred years later. From these first attempts, railway infrastructures, signalling and security have evolved and become more complex than those performed in its earlier stages. This book will provide readers a comprehensive technical guide, covering these topics and presenting a brief overview of selected railway systems in the world. The objective of the book is to serve as a valuable reference for students, educators, scientists, faculty members, researchers, and engineers.

\title{
How to reference
}

In order to correctly reference this scholarly work, feel free to copy and paste the following:

Clavel Edith, Meunier Gérard, Bellon Marc and Frugier Didier (2012). Study and Design of an Electro Technical Device for Safety on Railway Network, Infrastructure Design, Signalling and Security in Railway, Dr. Xavier Perpinya (Ed.), ISBN: 978-953-51-0448-3, InTech, Available from:

http://www.intechopen.com/books/infrastructure-design-signalling-and-security-in-railway/study-and-design-ofan-electro-technical-device-for-security-on-railway-network

\section{INTECH}

open science | open minds

\author{
InTech Europe \\ University Campus STeP Ri \\ Slavka Krautzeka 83/A \\ 51000 Rijeka, Croatia \\ Phone: +385 (51) 770447 \\ Fax: +385 (51) 686166 \\ www.intechopen.com
}

\author{
InTech China \\ Unit 405, Office Block, Hotel Equatorial Shanghai \\ No.65, Yan An Road (West), Shanghai, 200040, China \\ 中国上海市延安西路65号上海国际贵都大饭店办公楼405单元 \\ Phone: +86-21-62489820 \\ Fax: +86-21-62489821
}


(C) 2012 The Author(s). Licensee IntechOpen. This is an open access article distributed under the terms of the Creative Commons Attribution 3.0 License, which permits unrestricted use, distribution, and reproduction in any medium, provided the original work is properly cited. 